\title{
Soil Influences Colonization of Root-Associated Fungal Endophyte Communities of Maize, Wheat, and Their Progenitors
}

\author{
Deepak Bokati, ${ }^{1}$ José Herrera, ${ }^{2}$ and Ravin Poudel ${ }^{3}$ \\ ${ }^{1}$ Truman State University, 100 East Normal Street, Kirksville, MO 63501, USA \\ ${ }^{2}$ Western New Mexico University, 1000 W. College Avenue, Silver City, NM 88062, USA \\ ${ }^{3}$ Kansas State University, 4024 Throckmorton Plant Sciences Center, Manhattan, KS 66506, USA \\ Correspondence should be addressed to Deepak Bokati; db6368@truman.edu
}

Received 30 June 2015; Revised 21 December 2015; Accepted 24 December 2015

Academic Editor: Leo Van Griensven

Copyright (C) 2016 Deepak Bokati et al. This is an open access article distributed under the Creative Commons Attribution License, which permits unrestricted use, distribution, and reproduction in any medium, provided the original work is properly cited.

\begin{abstract}
Root-associated fungal endophytes are vital component of root microbiome as some mitigate their host's abiotic and biotic stress. We characterized root-associated fungal endophytes in cereal grains and their progenitors grown on two different soil-types. We aimed at determining how clay and desert soil affects the colonization of root fungal community. Both culture-dependent and culture-independent methods were employed to identify endophytes that successfully colonized greenhouse-grown host plants. The Internal Transcriber Spacer region of fungal ribosomal DNA was utilized for identification purposes. This study revealed soil as a prominent factor influencing the composition of microfungal communities inhabiting the roots of maize (Zea mays subsp. mays) and its conspecific progenitor, teosinte (Zea mays subsp. parviglumis). Similar results were found in wheat (Triticum aestivum subsp. aestivum) and its progenitor (Triticum monococcum subsp. monococcum). The multidimensional comparisons of MorisitaHorn similarity values of fungal colonists of various host plant taxa indicated that soil plays a primary role in shaping the root fungal community; a secondary effect was plant host identity, even when the plant host is a conspecific. Future studies focused on characterizing root endophytes in other cereal grains, and studying the effect of edaphic factors on fungal colonization, can ultimately contribute to crop productivity.
\end{abstract}

\section{Introduction}

Fungal endophytes associated with plants are reported to be ubiquitous in various environments [1-5] and geographical locations [6, 7]. Their relationship with plants varies from being symbiotic, mutualistic, or commensalistic [8], to at times even being pathogenic [9]. Some species of these endophytes are symbiotic to particular host plant species but can be pathogenic to other host species $[8,9]$. Symbiotic fungal endophytes are known to enhance plant fitness by conferring abiotic and biotic stress tolerance, and increasing biomass [10]. Most symbiotic root-associated fungal endophytes (RAFE) enhance absorption of water and minerals and in return get direct access to host carbohydrates [11].

The diversity of shoot (especially foliar) fungal endophytes has been well studied in various plants such as turf grasses [12, 13]; by comparison, RAFE are less understood, especially in cereal crops [14-18]. Similarly, studies examining the soil's effect on RAFE community of cereal grains such as wheat and maize have been rare; most of the published research investigated the identity and abundance of fungal colonists in (or on) the shoots of these crops [14, 16, 18-21]. Therefore, additional information about how soil influences the structure and composition of the RAFE community within wheat and maize would provide the scientific community with much needed information about how RAFE communities are structured and how these economically important and cosmopolitan grasses respond to changes in their soil environment.

The domestication of maize and wheat started approximately 10,000 years ago [22, 23]. During the course of domestication, genotypic and phenotypic changes as a result 
of constant artificial selection and demographic bottlenecks could have affected the structure and composition of the root fungal community. In particular, such changes might have decreased the colonization of some symbiotic endophytes associated with nutrient absorption and desiccation tolerance. For example, anthropogenic fertilization to increase levels of nutrients such as nitrogen and phosphorus in the soil might have favored less colonization of root endophytes that facilitate nutrient absorption in domesticated crops [24]. Furthermore, we suspect that additional and adaptive changes in the root physiology of domesticated varieties of cereal grains as a result of constant bottlenecking effects during the course of evolution might have selectively facilitated or impeded colonization or cohabitation by a subset of RAFE, or this change in root physiology might have favored some types of plant-fungal relationship.

Previous studies examining rhizosphere endophyte communities in different cultivars of canola reported a difference in endophyte community structure between the transgenic and nontransgenic cultivars [25]. The modification of the wheat genotype by disomic chromosome substitution had a specific effect that altered the composition of bacterial community $[25,26]$. Such evidence supports the plausibility that bottlenecks and continuous artificial selection during domestication might have been associated with favoring/eliminating particular endophytes in domesticated grains. Certain fungal endophytes that are known to mitigate challenges like nutrient deficiencies might have promoted the survival of maize and wheat progenitors in low nutrient environments; the reduction of such environmental deficiencies under domestication might have altered fungal community structure in domesticated grains.

Prior studies also have found that the soil environment plays a critical role in shaping the structure and composition of RAFE in several species of plants [1, 26-28]; however, to our knowledge, none of these studies examined how the soil-type affects the root microfungal community in wheat and maize. This study aims to examine whether different soil-types, desert or clay soil, influence RAFE colonization in maize and wheat. Characterizing and comparing the fungal communities among both the domesticated cereal grasses and their respective progenitors might help provide provisional understanding of domestication's effects on RAFE composition in these crops. RAFE characterization in cereal grains will also help us examine whether they harbor endophytes that are previously known to have a symbiotic relationship with other grass species.

We characterized RAFE in domesticated cereal grains (Triticum aestivum subsp. aestivum [wheat], and Zea mays subsp. mays [maize]) and their respective progenitors (Triticum monococcum subsp. monococcum [wild wheat], and Zea mays subsp. parviglumis [teosinte]), by growing them in desert, or clay soil-type. Although wheat and maize are major world crops, there is a very limited knowledge of their RAFE communities; moreover, most of the studies characterizing root fungal endophytes have been limited to culturedependent methods [17, 29]. We used 454 pyrosequencing (a more contemporary culture-independent method), in addition to the more typical culture-dependent method, to characterize the root fungal endophytes.

\section{Materials and Methods}

2.1. Seed Germination. Teosinte seeds (Accession PI 566691, Origin: Michoacan, Mexico) and maize seeds (B73; Accession PI 550473, Origin: Iowa, United States) were obtained from the North Central Regional Plant Introduction Station (Iowa State University, Ames, IA). Similarly, seeds of domesticated wheat (GSTR 11562, Origin: Washington, United States) and its progenitor (Accession PI 167526, Origin: Kirklareli, Turkey) were obtained from National Small Grains Germplasm Research Facility (Aberdeen, Idaho).

Based on preliminary germination trials, maize and teosinte seeds were exposed to $20 \%$ hydrogen peroxide solution (for two and five minutes, resp.) to help induce seed germination, and to surface-sterilize their seed coats [30]. Similarly, wheat and its progenitor seeds were also exposed to $20 \%$ hydrogen peroxide solution (for one minute). The surface sterilized seeds were then wrapped in sterile, wet paper towels and placed in a plastic zip lock bag at room temperature for germination [3]. Once germinated (five days for maize and six for teosinte, and five days for both wheat and its progenitor) seedlings were grown in the Truman State University (TSU) greenhouse.

2.2. Planting of Seedlings. Sterile cylindrical plastic pots were filled with either desert soil mixture or clay soil mixture. The desert soil (loamy sand) was collected along a $100 \mathrm{~m}$ transect from the Sevilleta National Wildlife Refuge in an area locally known as McKenzie Flats (coordinates: N $32^{\circ} 21.849 \mathrm{~W} 106^{\circ}$ 41.114) during the month of November 2012 and refrigerated $\left(4^{\circ} \mathrm{C}\right)$ until used. The desert soil mixture was a homogenous mixture of autoclaved potting soil (commercial professional growing mix, Berger, BM1) and New Mexican desert soil (in 1:1 ratio by volume). Similarly, the clay soil mixture was a 1:1 combination of autoclaved potting soil and clay soil collected from TSU farm (coordinates: N $40^{\circ} 10.79334$, W $92^{\circ}$ 36.10728). More specific information about the characteristics of the desert and clay soils we used can be obtained from the USDA web soil survey [31 April 4th 2015] database.

For simplicity, maize and teosinte plants grown in the desert soil mixture henceforth will be referred to as Dmaize and Dteosinte, respectively; those grown in the Missouri clay soil as Cmaize and Cteosinte, respectively. Similarly, wheat and its progenitor grown in desert soil will be referred to as Daestivum and Dmonococcum and those grown in clay soil mixture will be referred to as Caestivum and Cmonococcum. Also, the use of terms "wheat plants" and "maize plants" will represent both the domesticated and progenitor plants (e.g., wheat plants $=$ domesticated wheat and its progenitor).

A total of 20 seedlings each of domesticated wheat plants were planted in desert soil mixture as well as clay soil mixture. Similarly, 18 wheat progenitor seedlings were planted in clay soil mixture and 22 in desert soil mixture. A total of 20 seedlings each of maize and teosinte were planted in both soil mixtures. All potted plants (one pot per plant) were kept inside the TSU greenhouse, watered regularly, and pot 
placement was changed on alternate days to minimize any positional effects. Weeds growing around the plants were removed periodically. The domesticated wheat was harvested after 56 days of greenhouse growth. Wheat progenitor plants (70 days) and maize and teosinte plants (48 days) were also harvested after the indicated growth periods.

2.3. Root Sample Preparation. For each plant, approximately $6 \mathrm{~cm}$ healthy roots without visible necrosis or lesions were rinsed with high-pressurized tap water for five minutes with sporadic sprays of $1 \%$ Triton X solution [2]. After the rinsing, roots were observed under a dissecting microscope to make sure no soil particles were present on the root surface [31]. The roots were then surface sterilized using the 5\% Clorox and $1 \%$ Triton X solution for one minute, rinsed with distilled water for an additional minute, and blot-dried with sterile absorbent paper [4]. A portion of these blot-dried roots was immediately used for culture-dependent studies, and the remainder was stored at $-20^{\circ} \mathrm{C}$ for subsequent DNA extraction and molecular analyses.

2.4. Culture-Dependent Study. For each plant, cleaned roots were cut into small fragments approximately $1 \mathrm{~mm}$ long. Five randomly selected fragments were embedded into each of the three Malt Extract Agar (MEA) and three Potato Dextrose Sugar $(\mathrm{PDA})$ plates with antibiotics (streptomycin sulfate $=$ $0.02 \mathrm{~g} / \mathrm{mL}$, and chlortetracycline $=0.01 \mathrm{~g} / \mathrm{mL}$ ) [3]. Then the plates were incubated at $30^{\circ} \mathrm{C}$ for a minimum of two weeks with regular monitoring [4]. Any fungus observed on the plates was subcultured onto PDA plates with filter paper, scraped, and identified using molecular techniques $[3,32]$.

2.5. Culture-Independent Study. Root DNA was extracted from four randomly selected plants each of species-soil-type combination: Daestivum, Caestivum, Dmonococcum, Cmonococcum, Dteosinte, Dmaize, Cmaize, and Cteosinte using Qiagen DNeasy Plant Mini Kit (Qiagen Inc., Valencia, USA). The extracted DNA was then standardized to a concentration of $32 \mathrm{ng} / \mu \mathrm{L}$ utilizing the Nanodrop 2000 spectrophotometer at a wavelength of $260 \mathrm{~nm}$. Loci specific amplicon representing fungal communities was generated for ITS region of fungal rDNA utilizing specific primers (ITS1F and ITS4). Then, the amplicon generated per plant was tagged with unique molecular tags (barcode) using forward and reverse fusion primer sets, specially designed by incorporating the Roche A and $B$ adaptors as specified by the Roche 454 sequencing. The nested PCR amplicon was generated in $25 \mathrm{uL}$ reactions with Qiagen HotStar Taq master mix (Qiagen Inc., Valencia, USA), $1 \mathrm{uL}$ of each $5 \mathrm{uM}$ primer, and $1 \mathrm{uL}$ of template. Reactions were performed on ABI Veriti thermocyclers (Applied Biosystems, Carlsbad, USA) under the following thermal profile: $95^{\circ} \mathrm{C}$ for $5 \mathrm{~min}$, then $35 \mathrm{cycles}$ of $94^{\circ} \mathrm{C}$ for $30 \mathrm{sec}, 54^{\circ} \mathrm{C}$ for $40 \mathrm{sec}$, and $72^{\circ} \mathrm{C}$ for $1 \mathrm{~min}$, followed by one cycle of $72^{\circ} \mathrm{C}$ for $10 \mathrm{~min}$ and $4^{\circ} \mathrm{C}$ hold. Products were then pooled equimolar and each pool was cleaned with Diffinity RapidTip (Diffinity Genomics, West Henrietta, USA), and size selected using Agencourt AMPure XP (Beckman Coulter, Indianapolis, USA).
Cleaned amplicon pools were then quantified and sequenced following the Roche Titanium 454 FLX platform with titanium reagents and procedures. Molecular steps after the primary PCR reactions were performed at the Research and Testing Laboratories, LLC (Lubbock, USA), whereas the prior steps were performed at the TSU.

Sequences were clustered into taxonomic groups (species, genus, family, order, and class) at 96.5 percent similarity by Research and Testing Laboratory, LLC. Sequence clustering was based on UPARSE techniques [33]. Additional detailed information on data analysis pipeline involving denoising and chimera checking can be obtained from the data analysis methodology of the Research and Testing laboratory, LLC [34].

2.6. Analyses. Shannon diversity indices of RAFE communities were estimated utilizing both fungal species obtained from culture-independent (454 pyrosequencing) data, as well as morphotypes (surrogates for "species") obtained from culture-dependent data. Likewise, to compare the similarity of RAFE communities among plant groups, MorisitaHorn and Sorensen indices were assessed on both cultureindependent and culture-dependent data. The RAFE congruency distances, based on pairwise comparisons of MorisitaHorn or Sorensen values, were plotted utilizing STATISTICA's (version 8.0, Statsoft Inc. [http://www.statsoft.com/]) multidimensional scaling (MDS) module [35]. Dimensions one and two represent synthetic variables, generated to maximize the spread of congruency distances between pairs of dependent variable values.

Previous studies conducted throughout much of North America [2, 4, 31] found Darksidea spp. (Knapp et al. recently discovered this species as previously mistaken for Paraphaeosphaeria spp.) [35] as a prevalent fungal group inhabiting the roots of various grasses (i.e., Poaceae). Thus we assessed the likelihood of occurrence of this cosmopolitan microfungal group in the roots of wheat, maize, and their progenitors using SEQUENCHER (version 5.1, Gene Codes [http://genecodes.com/]). Around 40 sequences of Darksidea spp. previously obtained from other grasses (Genbank Accession nos. GQ923964-GQ923975) were aligned (90\% similarity and 40-base-pair overlap) with both the cultureindependent and culture-dependent dataset of each planttype, to calculate its colonization rate.

\section{Results}

3.1. Culturing RAFE. A total of 270 and 210 root segments were assessed from maize and wheat plants, respectively (Tables 1 and 2). In both grasses, Fusarium spp. and Alternaria spp. were most prevalent. Grasses grown in clay soil had larger Shannon diversity values than those grown in desert soil (Tables 1 and 2). Grasses grown in the same soil-type harbored similar fungal taxa (Figures 1 and 2).

3.2. Sequence Data. Altogether, we obtained a total of 148,579 fungal sequences from maize plants (mean $=37,145, \mathrm{SD}=$ 5275, $n=4$; Table 3). Similarly, 67,927 sequences were obtained from wheat plants $($ mean $=16,982, S D=926$, 
TABle 1: Culture-dependent data of maize (Zea mays subsp. mays) and teosinte (Zea mays subsp. parviglumis).

\begin{tabular}{|c|c|c|c|c|c|c|}
\hline Plants & \# of plants & Total morphotypes & $\begin{array}{c}\text { Mean }(\mathrm{SD}) \\
\text { number of } \\
\text { morphotypes/plants }\end{array}$ & \# of species & $\begin{array}{c}\text { Shannon } \\
\text { diversity } \\
\text { indices }\end{array}$ & $\begin{array}{l}\text { Morphotypes represented by the } \\
\text { most numerous sequences }\end{array}$ \\
\hline Dmaize & 7 & 8 & $1(2)$ & 4 & 0.90 & $\begin{array}{c}\text { Fusarium spp. (62\%) } \\
\text { Paraconiothyrium spp. }(25 \%) \\
\text { Alternaria spp. }(13 \%) \\
\end{array}$ \\
\hline Cmaize & 7 & 38 & $5(2)$ & 5 & 0.96 & $\begin{array}{l}\text { Fusarium spp. (54\%) } \\
\text { Alternaria spp. }(37 \%) \\
\text { Exserohilum spp. }(6 \%)\end{array}$ \\
\hline Dteosinte & 7 & 5 & $1(1)$ & 3 & 0.50 & $\begin{array}{c}\text { Fusarium spp. }(83 \%) \\
\text { Darksidea spp. }(17 \%) \\
\text { N/A }\end{array}$ \\
\hline Cteosinte & 7 & 25 & $5(3)$ & 4 & 1.11 & $\begin{array}{l}\text { Alternaria spp. }(56 \%) \\
\text { Fusarium spp. }(12 \%) \\
\text { Chaetomium spp. }(12 \%)\end{array}$ \\
\hline Total & 28 & 44 & $19(15)$ & 9 & 0.87 & $\begin{array}{l}\text { Fusarium spp. }(44 \%) \\
\text { Alternaria spp. }(39 \%) \\
\text { Chaetomium spp. }(4 \%)\end{array}$ \\
\hline
\end{tabular}

TABLE 2: Culture-dependent data of Triticum aestivum subsp. aestivum and Triticum monococcum subsp. monococcum.

\begin{tabular}{|c|c|c|c|c|c|c|}
\hline Plants & \# of plants & $\begin{array}{c}\text { Total } \\
\text { morphotypes }\end{array}$ & $\begin{array}{c}\text { Mean (SD) number of } \\
\text { morphotypes/plants }\end{array}$ & \# of species & $\begin{array}{c}\text { Shannon diversity } \\
\text { indices }\end{array}$ & $\begin{array}{c}\text { Morphotypes represented by the } \\
\text { most numerous sequences }\end{array}$ \\
\hline Daestivum & 9 & 48 & $5(4)$ & 8 & 1.71 & $\begin{array}{c}\text { Fusarium spp. }(42 \%) \\
\text { Darksidea spp. }(19 \%) . \\
\text { Cochliobolus spp. }(14 \%)\end{array}$ \\
\hline Caestivum & 9 & 24 & $3(3)$ & 7 & 2.04 & $\begin{array}{l}\text { Alternaria spp. (32\%) } \\
\text { Fusarium spp. }(23 \%) \\
\text { Periconia spp. }(13 \%)\end{array}$ \\
\hline Dmonococcum & 9 & 11 & $1(1)$ & 4 & 1.55 & $\begin{array}{l}\text { Darksidea spp. }(50 \%) \\
\text { Embellisia spp. }(30 \%) \\
\text { Cochliobolus spp. }(20 \%)\end{array}$ \\
\hline Cmonococcum & 9 & 15 & $2(2)$ & 9 & 2.02 & $\begin{array}{c}\text { Fusarium spp. }(27 \%) \\
\text { Alternaria spp. }(20 \%) \\
\text { Periconia spp. }(30 \%)\end{array}$ \\
\hline Total & 36 & 97 & $28(17)$ & 18 & 1.83 & $\begin{array}{l}\text { Fusarium spp. (28\%) } \\
\text { Alternaria spp. }(13 \%) \\
\text { Periconia spp. }(12 \%)\end{array}$ \\
\hline
\end{tabular}

TABle 3: Culture-independent data of maize (Zea mays subsp. mays) and teosinte (Zea mays subsp. parviglumis).

\begin{tabular}{|c|c|c|c|c|c|c|}
\hline Plants & \# of plants & Total sequences & $\begin{array}{l}\text { Mean (SD) number of } \\
\text { sequences/plants }\end{array}$ & \# of species & $\begin{array}{l}\text { Shannon diversity } \\
\text { indices }\end{array}$ & $\begin{array}{l}\text { Species represented by the most } \\
\text { numerous sequences }\end{array}$ \\
\hline Dmaize & 4 & 39971 & $9993(3729)$ & 22 & 1.63 & $\begin{array}{c}\text { Fusarium spp. (78\%) } \\
\text { Gibberella spp. }(9 \%) \\
\text { Ceratobasidium spp. (4\%) }\end{array}$ \\
\hline Cmaize & 4 & 41806 & $10452(5166)$ & 22 & 2.32 & $\begin{array}{l}\text { Fusarium spp. }(38 \%) \\
\text { Alternaria spp. }(32 \%) \\
\text { Gibberella spp. }(24 \%)\end{array}$ \\
\hline Dteosinte & 4 & 29814 & $7454(5276)$ & 22 & 1.97 & $\begin{array}{c}\text { Fusarium spp. (53\%) } \\
\text { Cochliobolus spp. }(14 \%) \\
\text { Podospora spp. }(10 \%)\end{array}$ \\
\hline Cteosinte & 4 & 36988 & 9247 (3183) & 30 & 2.62 & $\begin{array}{c}\text { Fusarium spp. }(38 \%) \\
\text { Alternaria spp. }(26 \%) \\
\text { Phoma spp. }(11 \%)\end{array}$ \\
\hline Total & 16 & 148579 & 37145 (5275) & 60 & 2.14 & $\begin{array}{c}\text { Fusarium spp. (51\%) } \\
\text { Alternaria spp. }(16 \%) \\
\text { Gibberella spp. }(9 \%)\end{array}$ \\
\hline
\end{tabular}




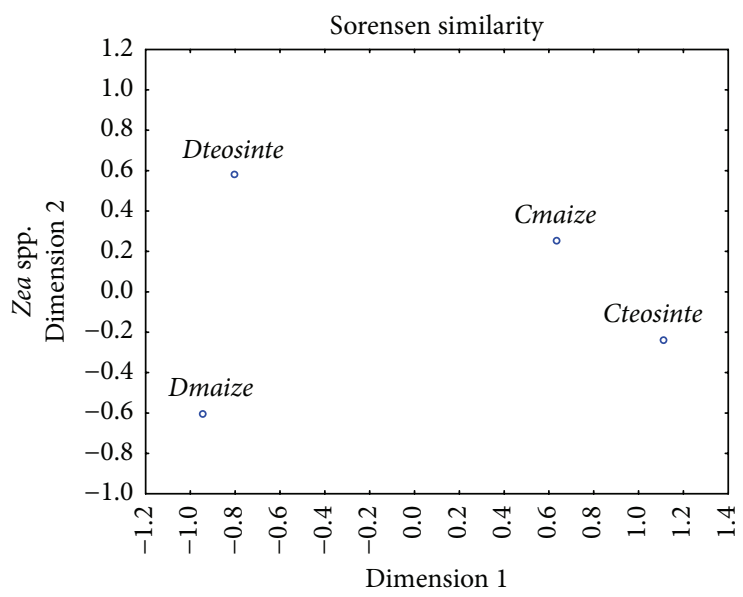

(a)

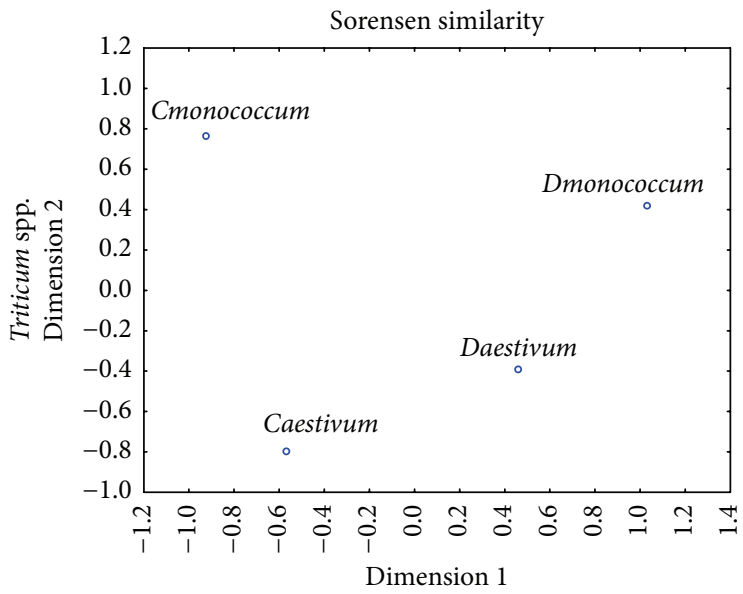

(c)

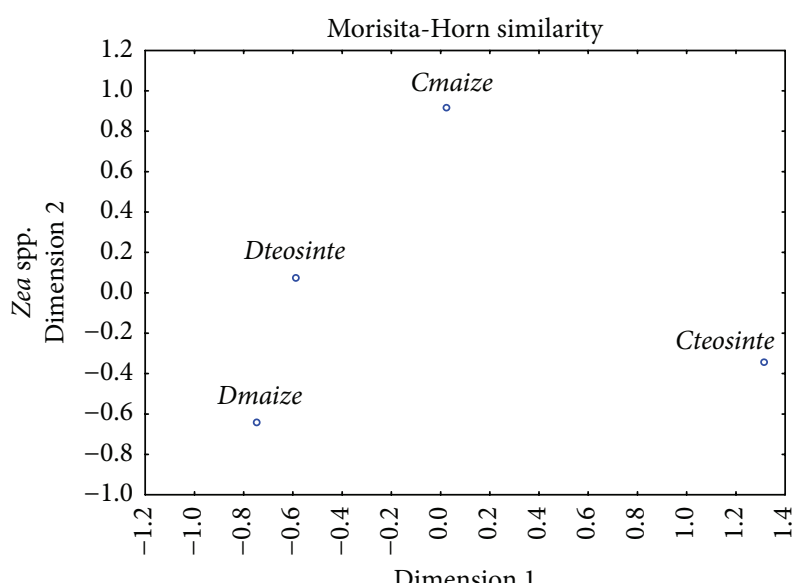

(b)

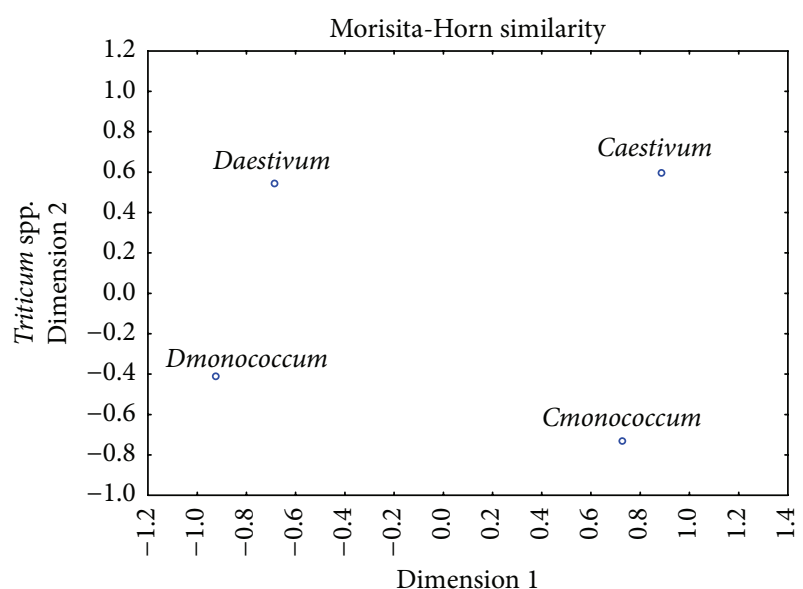

(d)

FIGURE 1: Multidimensional scaling diagrams generated using Sorensen ((a) and (c)) and Morisita-Horn ((b) and (d)) similarity values among fungal cultures isolated from root fragments of Zea spp. ((a) and (b)) and Triticum spp. ((c) and (d)) growing in either desert (DS) or clay (CS) soils. Dimensions one and two represent synthetic variables, generated to maximize the spread of congruency distances between pairs of dependent variable values. Maize (Zea mays subsp. mays) and teosinte (Zea mays subsp. parviglumis) plants grown in the desert soil mixture = Dmaize and Dteosinte, respectively; those grown in the Missouri clay soil as Cmaize and Cteosinte, respectively. Similarly, wheat (Triticum aestivum subsp. aestivum) and its progenitor, wild wheat (Triticum monococcum subsp. monococcum), grown in desert soil are indicated as Daestivum and Dmonococcum and those grown in clay soil mixture are labeled, Caestivum and Cmonococcum, respectively.

$n=4$; Table 4). In all grasses, fungal endophytes of the orders Hypocreales and Pleosporales were most common. Fusarium spp. (order Hypocreales) were the most prevalent microfungal taxa, constituting more than $25 \%$ of the fungal sequences. Alternaria spp., Gibberella spp., Cochliobolus spp., Periconia spp., Phoma spp., and Cercophora spp. were other commonly encountered fungal taxa (Tables 3 and 4).

Shannon diversity indices describing the diversity and abundance of fungal species were calculated from maize and wheat plants grown in desert and clay soil. Plants grown on the clay soil had greater fungal diversity values than those grown on the desert soil (Tables 3 and 4). However, one-way ANOVA showed no significant difference in mean Shannon diversity indices of maize and teosinte plants grown on each soil-type at level $P<0.05[F(3.12)=1.94, P=$ 0.177, ANOVA]. Similarly, wheat plants also indicated no significant difference between domesticated and progenitor plants grown on each soil-type at level $P<0.05[F(3,12)=$ $0.091, P=0.963$, ANOVA]. The Morisita-Horn and Sorenson similarity index values were generated to compare fungal species similarity among plants. These values indicated that plants grown on the same soil-type harbored similar fungal communities. The MDS diagrams then generated by pairwise comparisons of similarity values of culture-independent data clarified that plants grown on the same soil-type were colonized by similar microfungal community (Figures 1 and 2). This finding is consistent with culture-based data, where plants grown in the same soil harbored similar microfungal communities (Figures 1 and 2).

Furthermore, while assessing the sequences of Darksidea spp. (a genus frequently found in semiarid and arid grassland) $[2,31,35]$, we found that only desert-soil-grown plants, Dmaize and Dteosinte, harbored Darksidea spp. (0.0009\% and $0.0027 \%$ of their sequences, resp.). This soil-type-specific 


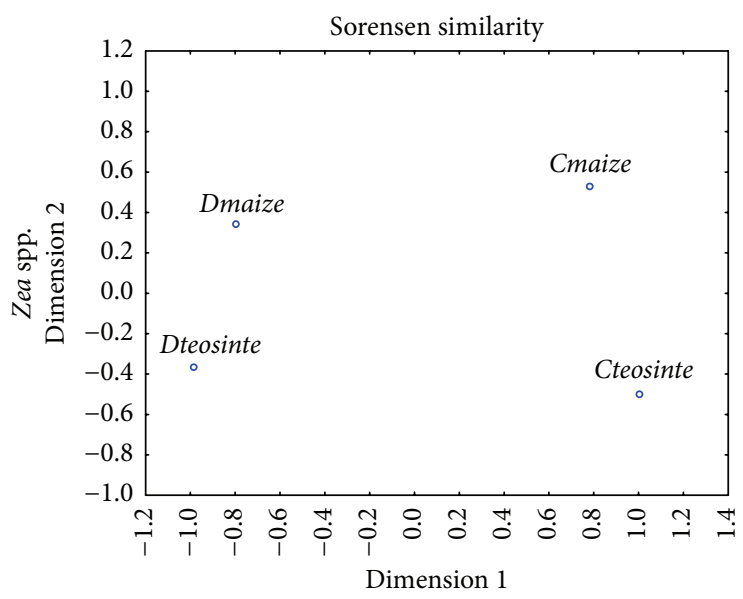

(a)

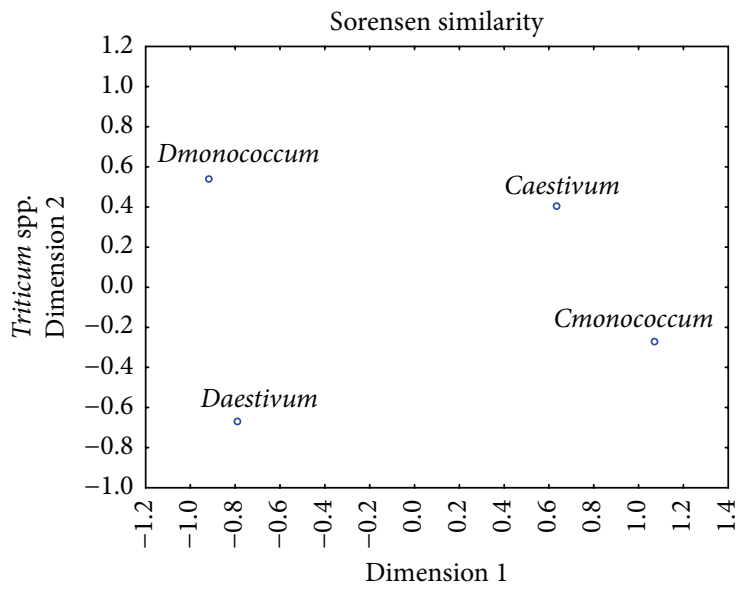

(c)

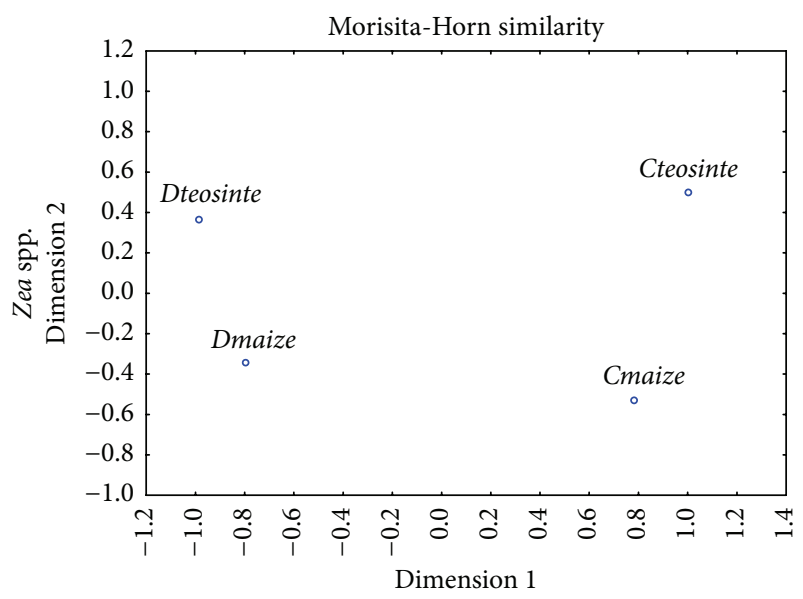

(b)

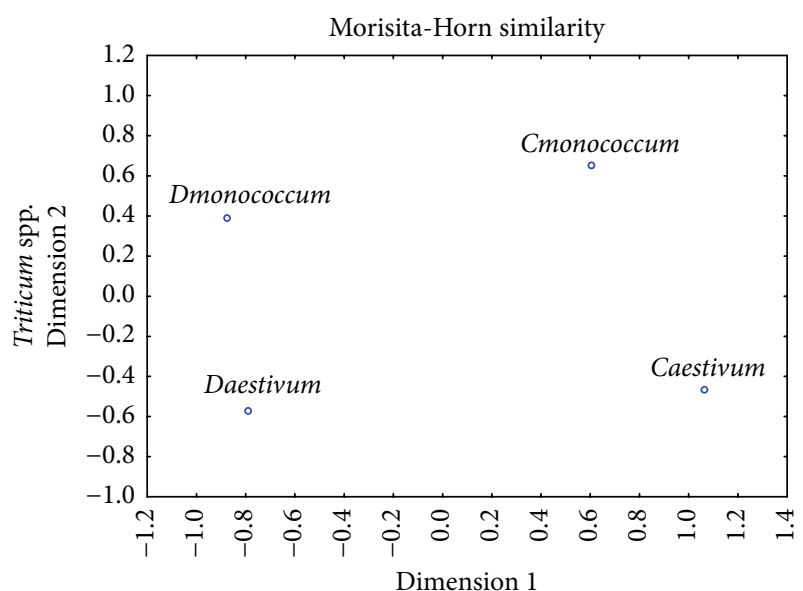

(d)

Figure 2: Multidimensional scaling diagrams generated using Sorensen ((a) and (c)) and Morisita-Horn ((b) and (d)) similarity values of sequence data, showing relative similarity in root-associated fungal communities colonizing Zea spp. ((a) and (b)) and Triticum spp. ((c) and (d)) in either desert (DS) or clay (CS) soils. Dimensions one and two represent synthetic variables, generated to maximize the spread of congruency distances between pairs of dependent variable values. Maize (Zea mays subsp. mays) and teosinte (Zea mays subsp. parviglumis) plants grown in the desert soil mixture = Dmaize and Dteosinte, respectively; those grown in the Missouri clay soil as Cmaize and Cteosinte, respectively. Similarly, wheat (Triticum aestivum subsp. aestivum) and its progenitor, wild wheat (Triticum monococcum subsp. monococcum), grown in desert soil will be referred to as Daestivum and Dmonococcum and those grown in clay soil mixture are labeled, Caestivum and Cmonococcum, respectively.

observation of Darksidea spp. also held true for wheat and its progenitor (Daestivum and Dmonococcum, 0.63 and 0.5 6\% of their sequences, resp.).

\section{Discussion}

This study documented soil as the prominent factor determining the composition and structure of microfungal communities inhabiting the roots of all grasses; that is, plants grown in the same soil-type harbored similar microfungal communities. Similar to our findings, research studying the effects of sandy soil and salt marshes on RAFE communities of 24 plant species in different habitats, coastal and inland, found soil-type influences on RAFE colonization [1]. MaciáVicente et al. [1] investigated the influence of the geomorphology and the physicochemical characteristics of the soil on microfungal colonization. Prominently, these researchers found that, as opposed to the geographic origin of the soil, the physicochemical characteristics of the soil such as the percentage of clay, silt, sand, and soil conductivity tend to play the most prominent role in fungal colonization [1]. Future studies focused on learning how these various individual physicochemical characteristics of soil exert influence on the root endophyte community will help us understand how each factor contributes to overall fungal colonization.

Fungal colonization of host plants at the early developmental stage may provide a crucial competitive advantage to these plants, potentially improving their ability to cope with stress and/or utilize limited resources. The effectiveness of microfungal communities to influence host plant fitness might not depend solely on the level of colonization or fungal diversity, but also on the timing of colonization [29]. 
TABle 4: Culture-independent data of Triticum aestivum subsp. aestivum and Triticum monococcum subsp. monococcum.

\begin{tabular}{|c|c|c|c|c|c|c|}
\hline Plants & \# of plants & Total sequences & $\begin{array}{l}\text { Mean }(\mathrm{SD}) \text { number of } \\
\text { sequences/plants }\end{array}$ & \# of species & $\begin{array}{c}\text { Shannon } \\
\text { diversity indices }\end{array}$ & $\begin{array}{l}\text { Species represented by the most } \\
\text { numerous sequences }\end{array}$ \\
\hline Daestivum & 4 & 15978 & $3995(1840)$ & 118 & 2.42 & $\begin{array}{c}\text { Fusarium spp. (28\%) } \\
\text { Gibberella spp. }(37 \%) \\
\text { Phoma spp. }(9 \%)\end{array}$ \\
\hline Caestivum & 4 & 17890 & 4473 (1970) & 112 & 2.48 & $\begin{array}{l}\text { Periconia spp. (38\%) } \\
\text { Fusarium spp. }(17 \%) \\
\text { Alternaria spp. }(11 \%)\end{array}$ \\
\hline Dmonococcum & 4 & 17637 & $4410(2866)$ & 89 & 2.42 & $\begin{array}{l}\text { Fusarium spp. }(26 \%) \\
\text { Alternaria spp. }(18 \%) \\
\text { Embellisia spp. }(23 \%)\end{array}$ \\
\hline Cmonococcum & 4 & 16422 & 4106 (1258) & 118 & 2.46 & $\begin{array}{l}\text { Fusarium spp. }(57 \%) \\
\text { Alternaria spp. }(8 \%) \\
\text { Cercophora spp. }(7 \%)\end{array}$ \\
\hline Total & 16 & 67927 & $16982(926)$ & 248 & 2.45 & $\begin{array}{l}\text { Fusarium spp. (31\%) } \\
\text { Alternaria spp. }(12 \%) \\
\text { Gibberella spp. }(12 \%)\end{array}$ \\
\hline
\end{tabular}

Early colonization of symbiotic endophytes might play a vital role in enhancing absorption of nutrients and water and mitigating desiccation tolerance, thus conferring accelerated development. Maize seedlings grown in desert soil reached the 4-leaf stage (10th day, average value) earlier, compared to plants grown in clay soil (18th day) (J. Herrera and D. Bokati, unpublished data from greenhouse-grown maize and wheat grasses). This might have resulted from earlier colonization of symbiotic microfungal communities present in desert soil. However, comparing the shoot dry mass of the plants grown in different soils upon harvesting indicated no significant difference at level $P<0.05[F(3,20)=0.88, P=0.468$, ANOVA] (J. Herrera and D. Bokati, unpublished data from greenhouse-grown maize and wheat grasses). Any advantage to host plants provided by earlier fungal colonization could be relatively unimportant when host plants are in favorable conditions, as was the case in our greenhouse study. Future studies could assess whether endophytes can boost early growth in crops in stressful environments.

Pleosporales taxa made up the greatest proportion of the microfungal community in Chihuahuan Desert soil [30], and it is highly prevalent in native grasses of the Chihuahuan Desert, such as Bouteloua gracilis [2, 30]. A particular group of fungal species known as Dark Septate Endophytes (DSE) of order Pleosporales are prevalent microfungal taxa of Chihuahuan Desert grasses [2, 30]. DSE, a conidial or sterile fungus, are reported to colonize around 600 plant species representing 320 genera and about 300 families [36]. Symbiotic DSE seems to gain access to carbohydrates from hosts' cells, and, in return, hosts benefit from improved nutrient and water acquisition [11]. Some of these DSE are known to mitigate desiccation stress $[30,32]$. In this study, the decrease in Pleosporales colonization in Dmaize (2\%) relative to its progenitor Dteosinte (26\%) may mean that genotypic and phenotypic changes during maize domestication could have decreased its dependence on Pleosporales.

Cosmopolitan Pleosporalean fungi, Darksidea spp., colonize grass species inhabiting different environments and geographic regions [2-6, 30, 31, 35] (J. Herrera, and R. Poudel, unpublished data from grasses in Nepal and South Africa). All of the plants grown in the desert soil were colonized by these particular fungi, and only these plants supported these fungi. Some taxa of DSE fungi, especially of order Pleosporales, are known to provide desiccation tolerance [4]. The uniquely biased colonization of desert-soil-grown cereal grains by Darksidea spp. signals its potential for symbiotic relationships with these host plant taxa, particularly in arid environments. Also, this ability of Darksidea spp. to colonize roots of a wide variety of grasses may be evidence of a fairly ancient relationship between these particular fungal taxa and host plants in the Poaceae [2] (J. Herrera, and R. Poudel, unpublished data from grasses in Nepal and South Africa). Additional studies on a more diverse set of grasses can test this assumption more rigorously.

Even though plants grown in the same soil harbored similar fungal taxa, they were typically in different concentrations. For example, based on culture-independent data, a greater number of Fusarium spp. were observed in Dmaize (78\%) than in Dteosinte (53\%) (Table 3); this difference might have been the result of the host's role in microfungal colonization, as found in other studies $[10,11,37]$. Since this was a greenhouse experiment, plants were provided with optimal growth conditions. However in farms or natural ecosystems those plants might not have such moderate growing conditions, a situation that could alter fungal colonization and fungal community development. It would be especially interesting to investigate root fungal community in arid lands because many studies have found that some symbiotic fungal endophytes tend to selectively colonize in stressful environmental conditions [38]. Thus, additional studies in more variable and realistic environmental conditions are needed to determine some of the nuances of the effect soil-type has on fungal colonization of grass roots.

\section{Conflict of Interests}

There is no conflict of interests to declare. 


\section{Acknowledgments}

The authors would like to thank Michael Kelrick for editing and providing suggestions on the paper, Laura Fielden for her mentorship and advice throughout the duration of the research, Mark Campbell, John Ma, and Clayton Dillavou for helping with greenhouse experiments, Daniel Creagor for endophyte isolation, and Don Natvig, Brandon Spratt, Suman Parajuli, and Sujana Parajuli for helping with soil collection. Grateful acknowledgment is made for the financial support towards Truman State University (TSU) graduate research stipend, TSU GIASR grant, and National Science Foundation grant (DEB-0715746).

\section{References}

[1] J. G. Maciá-Vicente, H.-B. Jansson, S. K. Abdullah, E. Descals, J. Salinas, and L. V. Lopez-Llorca, "Fungal root endophytes from natural vegetation in Mediterranean environments with special reference to Fusarium spp," FEMS Microbiology Ecology, vol. 64, no. 1, pp. 90-105, 2008.

[2] J. Herrera, H. H. Khidir, D. M. Eudy, A. Porras-Alfaro, D. O. Natvig, and R. L. Sinsabaugh, "Shifting fungal endophyte communities colonize Bouteloua gracilis: effect of host tissue and geographical distribution," Mycologia, vol. 102, no. 5, pp. 10121026, 2010.

[3] J. Herrera, R. Poudel, and D. Bokati, "Assessment of rootassociated fungal communities colonizing two species of tropical grasses reveals incongruence to fungal communities of North American native grasses," Fungal Ecology, vol. 6, no. 1, pp. 65-69, 2013.

[4] H. H. Khidir, D. M. Eudy, A. Porras-Alfaro, J. Herrera, D. O. Natvig, and R. L. Sinsabaugh, "A general suite of fungal endophytes dominate the roots of two dominant grasses in a semiarid grassland," Journal of Arid Environments, vol. 74, no. 1, pp. 35-42, 2010.

[5] A. Porras-Alfaro, J. Herrera, R. L. Sinsabaugh, K. J. Odenbach, T. Lowrey, and D. O. Natvig, "Novel root fungal consortium associated with a dominant desert grass," Applied and Environmental Microbiology, vol. 74, no. 9, pp. 2805-2813, 2008.

[6] J. Herrera, R. Poudel, and H. H. Khidir, "Molecular characterization of coprophilous fungal communities reveals sequences related to root-associated fungal endophytes," Microbial Ecology, vol. 61, no. 2, pp. 239-244, 2011.

[7] M. Weiß, Z. Sýkorová, S. Garnica et al., "Sebacinales everywhere: previously overlooked ubiquitous fungal endophytes," PLoS ONE, vol. 6, no. 2, Article ID e16793, 2011.

[8] S. Smith and D. Read, Mycorrhizal Symbiosis, Academic Press, London, UK, 3rd edition, 2008.

[9] N. C. Johnson, J. H. Graham, and F. A. Smith, "Functioning of mycorrhizal associations along the mutualism-parasitism continuum," New Phytologist, vol. 135, no. 4, pp. 575-586, 1997.

[10] R. J. Rodriguez, J. F. White Jr., A. E. Arnold, and R. S. Redman, "Fungal endophytes: diversity and functional roles," New Phytologist, vol. 182, no. 2, pp. 314-330, 2009.

[11] A. Jumpponen, "Dark septate endophytes-are they mycorrhizal?” Mycorrhiza, vol. 11, no. 4, pp. 207-211, 2001.

[12] K. Saikkonen, K. Ruokolainen, O. Huitu et al., "Fungal endophytes help prevent weed invasions," Agriculture, Ecosystems \& Environment, vol. 165, pp. 1-5, 2013.
[13] M. Żurek, B. Wiewióra, G. Zurek, and M. Prończuk, "Occurrence of endophyte fungi on grasses in Poland-review," Fungal Ecology, vol. 5, no. 3, pp. 353-356, 2012.

[14] S. L. Clement, A. D. Wilson, D. G. Lester, and C. M. Davitt, "Fungal endophytes of wild barley and their effects on Diuraphis noxia population development," Entomologia Experimentalis et Applicata, vol. 82, no. 3, pp. 275-281, 1997.

[15] J. Dingle and P. A. McGee, "Some endophytic fungi reduce the density of pustules of Puccinia recondita f. sp. tritici in wheat," Mycological Research, vol. 107, no. 3, pp. 310-316, 2003.

[16] P. W. Crous, O. Petrini, G. F. Marais, Z. A. Pretorius, and F. Rehder, "Occurrence of fungal endophytes in cultivars of Triticum aestivum in South Africa," Mycoscience, vol. 36, no. 1, pp. 105-111, 1995.

[17] P. J. Fisher, O. Petrini, and H. M. L. Scott, "The distribution of some fungal and bacterial endophytes in maize (Zea mays L.)," New Phytologist, vol. 122, no. 2, pp. 299-305, 1992.

[18] S. Larran, A. Perelló, M. R. Simón, and V. Moreno, "The endophytic fungi from wheat (Triticum aestivum L.)," World Journal of Microbiology and Biotechnology, vol. 23, no. 4, pp. 565572, 2007.

[19] C. W. Bacon and D. M. Hinton, "Symptomless endophytic colonization of maize by Fusarium moniliforme," Canadian Journal of Botany, vol. 74, no. 8, pp. 1195-1202, 1996.

[20] J. R. Leake, A. L. Duran, K. E. Hardy et al., "Biological weathering in soil: the role of symbiotic root-associated fungi biosensing minerals and directing photosynthate-energy into grainscale mineral weathering," Mineralogical Magazine, vol. 72, no. 1, pp. 85-89, 2008.

[21] R. Sapkota, K. Knorr, L. N. Jørgensen, K. A. O’Hanlon, and M. Nicolaisen, "Host genotype is an important determinant of the cereal phyllosphere mycobiome," New Phytologist, vol. 207, no. 4, pp. 1134-1144, 2015.

[22] A. Studer, Q. Zhao, J. Ross-Ibarra, and J. Doebley, "Identification of a functional transposon insertion in the maize domestication gene tbl," Nature Genetics, vol. 43, no. 11, pp. 1160-1163, 2011.

[23] N. A. Eckardt, "Evolution of domesticated bread wheat," The Plant Cell, vol. 22, no. 4, p. 993, 2010.

[24] J. Krauss, S. A. Härri, L. Bush et al., "Effects of fertilizer, fungal endophytes and plant cultivar on the performance of insect herbivores and their natural enemies," Functional Ecology, vol. 21, no. 1, pp. 107-116, 2007.

[25] S. D. Siciliano, C. M. Theoret, J. R. De Freitas, P. J. Hucl, and J. J. Germida, "Differences in the microbial communities associated with the roots of different cultivars of canola and wheat," Canadian Journal of Microbiology, vol. 44, no. 9, pp. 844-851, 1998

[26] M. Girlanda, S. Perotto, and A. Luppi, "Molecular diversity and ecological roles of mycorrhiza-associated sterile fungal endophytes in Mediterranean ecosystems," in Microbial Root Endophytes, B. E. Schulz, C. C. Boyle, and T. Sieber, Eds., pp. 207-226, Springer, Berlin, Germany, 2006.

[27] C. R. Grippa, M. P. Hoeltgebaum, and S. L. Stürmer, "Occurrence of arbuscular mycorrhizal fungi in bromeliad species from the tropical Atlantic forest biome in Brazil," Mycorrhiza, vol. 17, no. 3, pp. 235-240, 2007.

[28] J. R. Barrow, "Atypical morphology of dark septate fungal root endophytes of Bouteloua in arid southwestern USA rangelands," Mycorrhiza, vol. 13, no. 5, pp. 239-247, 2003.

[29] T. P. McGonigle, M. H. Miller, and D. Young, "Mycorrhizae, crop growth, and crop phosphorus nutrition in maize-soybean 
rotations given various tillage treatments," Plant and Soil, vol. 210, no. 1, pp. 33-42, 1999.

[30] A. Porras-Alfaro, J. Herrera, D. O. Natvig, K. Lipinski, and R. L. Sinsabaugh, "Diversity and distribution of soil fungal communities in a semiarid grassland," Mycologia, vol. 103, no. 1, pp. 10-21, 2011.

[31] J. Herrera, R. P. Oudel, K. A. Nebel, and S. L. Collins, "Precipitation increases the abundance of some groups of root-associated fungal endophytes in a semiarid grassland," Ecosphere, vol. 2, no. 4, article 50, 2011.

[32] A. Porras-Alfaro, J. Herrera, D. O. Natvig, and R. L. Sinsabaugh, "Effect of long-term nitrogen fertilization on mycorrhizal fungi associated with a dominant grass in a semiarid grassland," Plant and Soil, vol. 296, no. 1, pp. 65-75, 2007.

[33] http://www.researchandtesting.com/docs/Data_Analysis_Methodology.pdf.

[34] J. B. Kruskal, "Multidimensional scaling by optimizing goodness of fit to a nonmetric hypothesis," Psychometrika, vol. 29, no. 1, pp. 1-27, 1964.

[35] D. Knapp, G. Kovács, E. Zajta, J. Groenewald, and P. Crous, "Dark septate endophytic pleosporalean genera from semiarid areas," Persoonia, vol. 35, no. 1, pp. 87-100, 2015.

[36] A. R. I. Jumpponen and J. M. Trappe, "Dark septate endophytes: a review of facultative biotrophic root-colonizing fungi," New Phytologist, vol. 140, no. 2, pp. 295-310, 1998.

[37] H. P. Bais, T. L. Weir, L. G. Perry, S. Gilroy, and J. M. Vivanco, "The role of root exudates in rhizosphere interactions with plants and other organisms," Annual Review of Plant Biology, vol. 57, no. 1, pp. 233-266, 2006.

[38] M. Hubbard, J. J. Germida, and V. Vujanovic, "Fungal endophytes enhance wheat heat and drought tolerance in terms of grain yield and second-generation seed viability," Journal of Applied Microbiology, vol. 116, no. 1, pp. 109-122, 2014. 

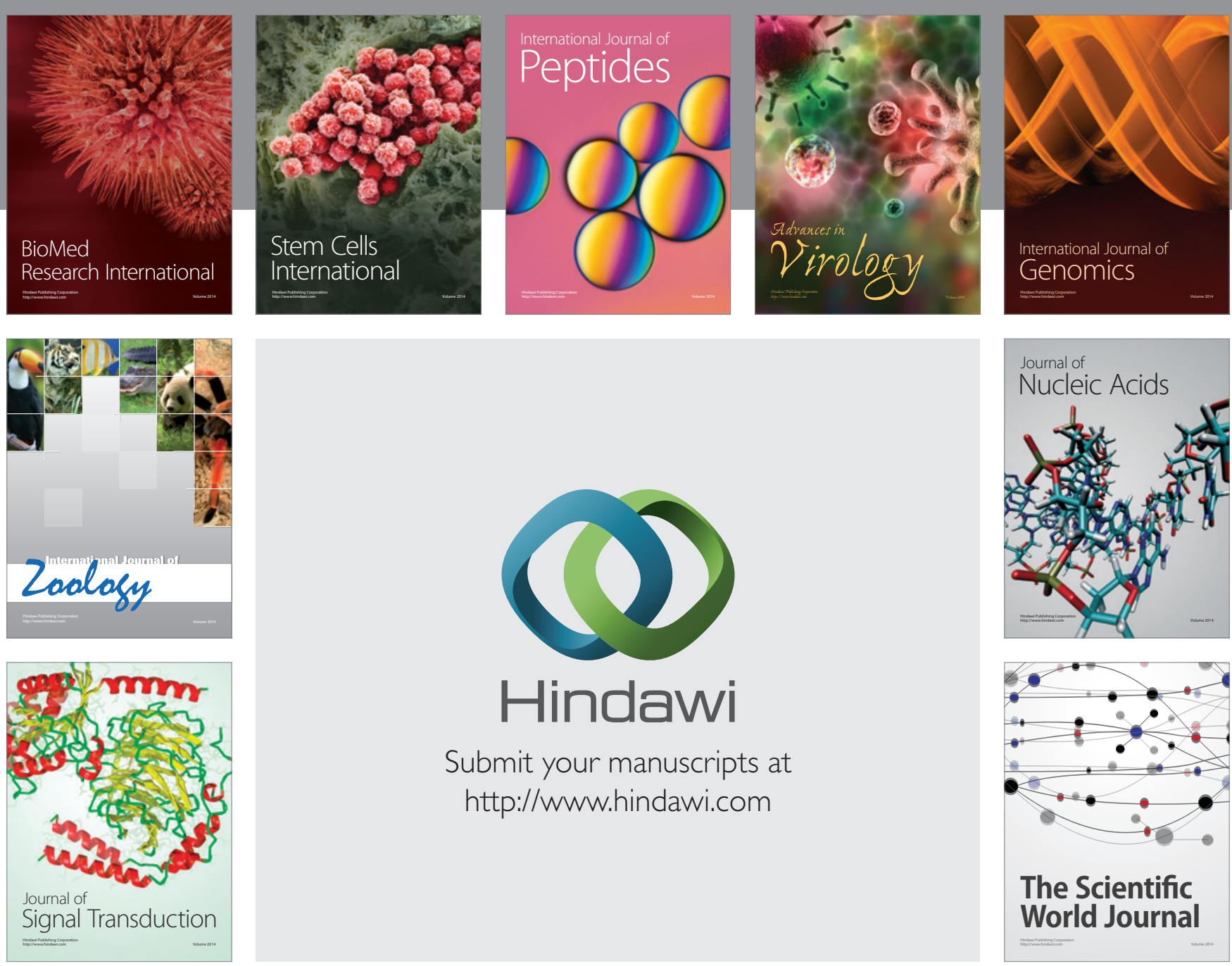

Submit your manuscripts at

http://www.hindawi.com
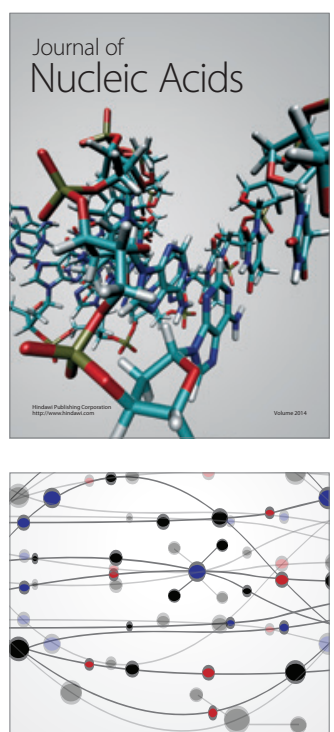

The Scientific World Journal
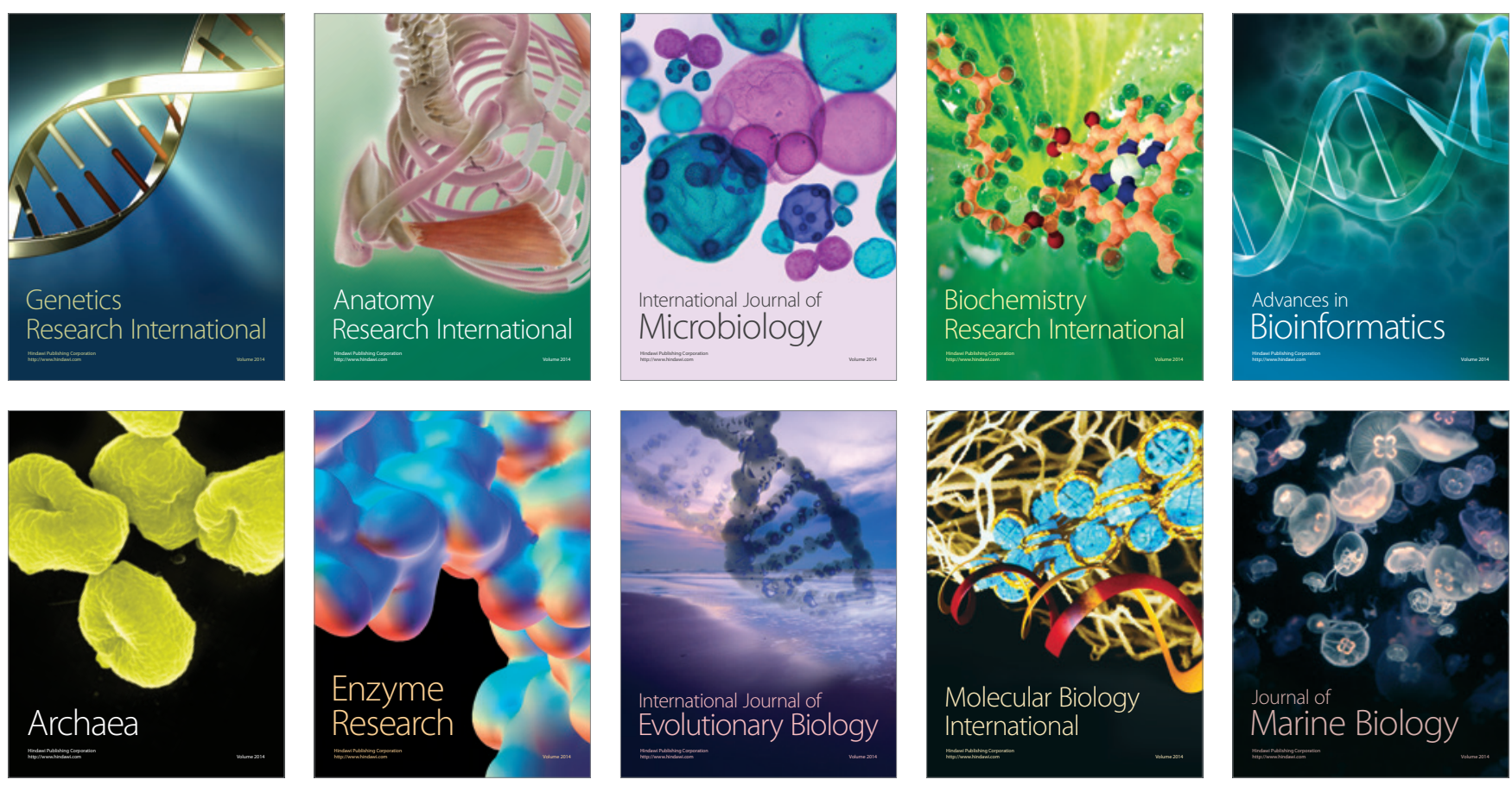